\title{
Solid pseudopapillary neoplasms of the pancreas show an interruption of the Wnt-signaling pathway and express gene products of 11q
}

\author{
Katharina Tiemann, Ulrike Heitling, Markus Kosmahl and Günter Klöppel \\ Department of Pathology, University of Kiel, Kiel, Germany
}

\begin{abstract}
Solid pseudopapillary neoplasms of the pancreas almost consistently show a $\beta$-catenin mutation activating the Wnt-signaling pathway, resulting in overexpression of cyclin D1, but not in overt malignancy of this tumor. Besides cyclin D1, a set of markers (ie FLI-1, CD56 and progesterone receptor), whose genes map to chromosome 11q, are frequently expressed in solid pseudopapillary neoplasms. Chromosome 11q is a region that is also often affected in pancreatic neuroendocrine tumors. This immunohistochemical study was undertaken to gain insights into the downstream regulation of the Wnt-signaling pathway and the significance of overexpressed gene products belonging to chromosome 11q for the tumorigenesis in solid pseudopapillary neoplasms. Fourteen solid pseudopapillary neoplasms were analyzed for the expression of cyclin-dependent kinase inhibitors p21, p27, p16 and hyperphosphorylated retinoblastoma (pRb) proteins. In an extended series of 93 solid pseudopapillary neoplasms, $\beta$-catenin, cyclin D1, FLI-1 and CD56 expression was examined and compared with that in 22 pancreatic neuroendocrine tumors. Solid pseudopapillary neoplasms $(98 \%)$ showed aberrant expression of $\beta$-catenin with a concomitant cyclin D1 expression in $69 \%$ of the cases, but no expression of pRb $(0 \%)$ was found. p27 and p21 were expressed in $100 \%(14 / 14)$ and $86 \%(12 / 14)$ of the cases, but only $2 / 14(14 \%)$ were positive for p16. FLI-1 was expressed in $63 \%$ of solid pseudopapillary neoplasms, but only in $1 / 22$ pancreatic neuroendocrine tumors $(5 \%)$, cyclin D1 expression was present in $14 \%$ of the latter. We conclude that in solid pseudopapillary neoplasms the activated Wnt-signaling pathway is disrupted, and that p21 and p27 are contributing to this fact by blocking of the hyperphosphorylation of the Rb protein, thus causing the very low proliferation rate characterizing the solid pseudopapillary neoplasms. The accumulation of high expression of proteins whose genes are located on chromosome 11q is characteristic of solid pseudopapillary neoplasms, but not of pancreatic neuroendocrine tumors.
\end{abstract}

Modern Pathology (2007) 20, 955-960; doi:10.1038/modpathol.3800902; published online 13 July 2007

Keywords: Wnt pathway; solid pseudopapillary neoplasm; neuroendocrine tumor; chromosome 11q; p27

Solid pseudopapillary neoplasms of the pancreas, though histopathologically well recognized, remain enigmatic tumors as far as their histogenesis is concerned. Genetically, solid pseudopapillary neoplasms are characterized by a mutation of the $\beta$-catenin gene in exon $3,{ }^{1,2}$ resulting in an aberrant immunohistochemical expression pattern of $\beta$-catenin. This expression is accompanied by cyclin D1 overexpression, a cell cycle associated protein and primary target of Wnt signaling, that has also been reported in neuroendocrine tumors. ${ }^{3,4}$ Cyclin D1 expression is often associated with tumor progres-

Correspondence: Dr K Tiemann, MD, Department of Pathology, University of Kiel, Michaelisstr. 11, 24105 Kiel, Germany.

E-mail: k.peters@path.uni-kiel.de

Received 2 February 2007; revised 15 May 2007; accepted 17 May 2007; published online 13 July 2007 sion in various cancers and a marker of mantle cell lymphoma. ${ }^{5,6}$

Phenotypically, most or a considerable number of solid pseudopapillary neoplasms express markers that are related to neuroendocrine features. These markers include synaptophysin, CD56, the progesterone receptor, NSE and CD10. ${ }^{7,8}$ Recently, we showed that solid pseudopapillary neoplasms express FLI-1, which has also been demonstrated in neuroendocrine tumors of the skin (so-called Merkel cell carcinomas). ${ }^{9}$ Finally, a non-mutation-mediated activation of c-kit was demonstrated in about $50 \%$ of solid pseudopapillary neoplasms, ${ }^{10}$ a finding similar to that seen in neuroendocrine small cell carcinomas of the lung. ${ }^{11,12}$

When the genes encoding for the above mentioned markers are localized, it is striking that many of them reside on chromosome 11q, a chromosomal 
area that also is involved in the genetics of pancreatic neuroendocrine tumors because it harbors the MEN1 gene. ${ }^{13}$ The genes that map to the long arm of chromosome 11 include the cyclin D1 gene, which maps to 11q13, the CD56 (NCAM) and FLI-1 genes, which are located on 11q23 and 11q24, respectively, and the progesterone receptor, which is found on $11 \mathrm{q} 22$.

The aim of this study was to get more insight into the mechanisms of the Wnt pathway in solid pseudopapillary neoplasms that has been activated by the mutated $\beta$-catenin gene. Furthermore, we wanted to examine the expression of a group of markers that are frequently expressed in solid pseudopapillary neoplasms and that reside on chromosome 11q. By comparing their expression pattern with that of neuroendocrine tumors of the pancreas we investigated, whether these tumors bear some resemblance to each other with regard to the chromosome 11q set of markers. To this end, we examined a large series of solid pseudopapillary neoplasms and neuroendocrine tumors from the pancreas.

\section{Materials and methods}

The study was performed on tumor resection specimens. The cases were retrieved from the consultation files of the Departments of Pathology and Pediatric Pathology of the University of Kiel, Germany. Clinical information was obtained from the patients' records. The study included 93 cases of solid pseudopapillary neoplasms, two of which showed liver metastasis or gross invasion and 22 cases of well-differentiated neuroendocrine tumors of the pancreas with metastasis or invasion. The pancreatic neuroendocrine tumors were classified according to the WHO classification of tumors of the endocrine pancreas. ${ }^{14}$ Table 1 summarizes tumor types, age and sex of the patients.

\section{Immunohistochemistry}

For immunohistochemical staining the following antibodies were used at the stated dilutions: FLI-1 (Santa Cruz Biotechnology, Santa Cruz, CA, USA; 1:100); NCAM (CD56) (Novocastra, Newcastle upon Tyne, UK; 1:50); $\beta$-catenin (Zymed, San Francisco, CA, USA; 1:250); cyclin D1 (Novocastra; 1:10), hyperphosphorylated retinoblastoma protein (Phar- mingen, Heidelberg, Germany; 1:100), p16 (NeoMarkers, Newmarket, UK; 1:50), p21 (Novocastra; 1:10), p27 (DAKOCytomation, Glostrup, Denmark; 1:50). Immunohistochemical staining was performed using a standard protocol with heat-induced antigen retrieval in citrate buffer using a pressure cooker, as described previously. ${ }^{7}$ Staining was visualized using the avidin-biotin method with $3,3^{\prime}$-diaminobenzidine as chromogen. The cutoff level for marker expression was 5\%. For some cases, the complete marker panel could not be used because of lack of tumor tissue in the paraffin blocks. pRb, p16, p21 and p27 expression was evaluated in 14 cases of solid pseudopapillary neoplasms, including the invasive ones.

\section{Statistical Analysis}

For the statistical analysis the $\chi^{2}$-test (SPSS ${ }^{\odot} 13.0$ ) was used. Differences were considered significant if $P<0.05$.

\section{Results}

\section{Histopathology}

All solid pseudopapillary neoplasms showed the histological pattern typical for these tumors. In brief, solid pseudopapillary neoplasms revealed admixed solid and pseudopapillary areas with necrosis or cholesterol deposits as signs of regression. The nuclei were uniform and seldom showed nucleoli. Mitoses were absent.

Pancreatic neuroendocrine tumors showed a solid or trabecular growth pattern with occasional gland formation. Advanced stage was confirmed by local invasion and/or metastases.

\section{Immunohistochemistry}

Solid pseudopapillary neoplasms showed the expected aberrant $\beta$-catenin expression pattern in $98 \%$ (91/93) of the cases, cyclin D1 expression was noted in $69 \%$ (62/90; Figures 1 and $2 \mathrm{a}$ ) with $60 \%$ of the cases exhibiting a reactivity in $10-50 \%$ of the nuclei. No case showed expression of $\mathrm{pRb}(0 / 14)$, while p27 and p21 were present in $100 \%(14 / 14)$ and $86 \%(12 / 14)$ of the cases investigated, respectively (Figure 2b and c). p21 showed a usually weak staining pattern, the expression ranged between 5

Table 1 Clinicopathological data on the investigated tumors

\begin{tabular}{lcccc}
\hline Tumor type & Age, mean & Age, range & Sex, female/male & Number of cases \\
\hline Solid pseudopapillary neoplasm & 32 & $11-71$ & $63: 7^{\mathrm{a}}$ & \\
Pancreatic neuroendocrine tumor & 55 & $36-75$ & $11: 11$ & 93 \\
\hline
\end{tabular}

\footnotetext{
${ }^{\mathrm{a}}$ Sex of the other 23 patients unknown.
} 


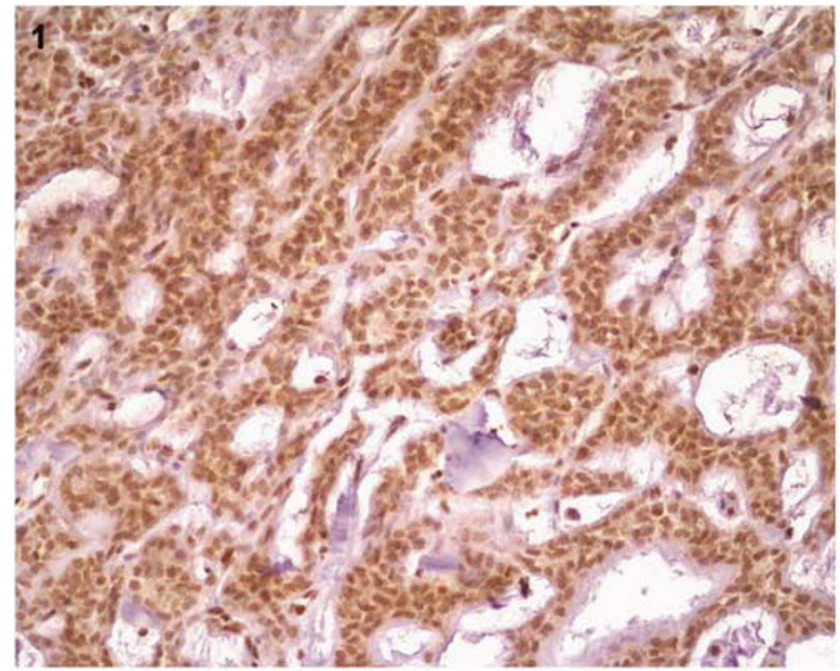

Figure 1 FLI-1 expression in a solid pseudopapillary neoplasm.

and $60 \%$, whereas p27 usually exhibited a moderate to strong reaction in $70 \%$ to almost $100 \%$ of the tumor cells. p16 was detected only in two cases, these patients were 63 and 71 years old.

FLI-1 expression was observed in 58/92 solid pseudopapillary neoplasms (63\%; Figure 1), 64\% of these showing a reactivity in $10-50 \%$ of the nuclei. CD56 was detected in 97\% (86/89) of solid pseudopapillary neoplasms.

In the pancreatic neuroendocrine tumors, normal membranous expression of $\beta$-catenin was observed in pancreatic neuroendocrine tumors (91\%). Cyclin D1 expression was not regularly observed in PETs (3/22 positive; $14 \%)$.

FLI-1 was only expressed in one pancreatic neuroendocrine tumor (1/22; 5\%). Expression of CD56 was $50 \%$ in pancreatic neuroendocrine tumors (Table 2).

No marker showed a positive correlation with advanced tumor stage, neither in solid pseudopapillary neoplasms (including only two invasive cases) nor in the pancreatic neuroendocrine tumors. A lack of FLI-1 expression correlated significantly with a lack of cyclin D1 expression in pancreatic neuroendocrine tumors (19/22). No other significant correlations were found.

The results are summarized in Table 2 for the marker expression in both investigated tumor entities and in Table 3 for cell cycle-associated markers in solid pseudopapillary neoplasms.

\section{Discussion}

The cellular origin of solid pseudopapillary neoplasms is still an unresolved issue. It has been impossible to link the solid pseudopapillary neoplasm cells to any specific cell type of the pancreas or extrapancreatic tissues. However, this tumor, which seems to come from nowhere, shows some
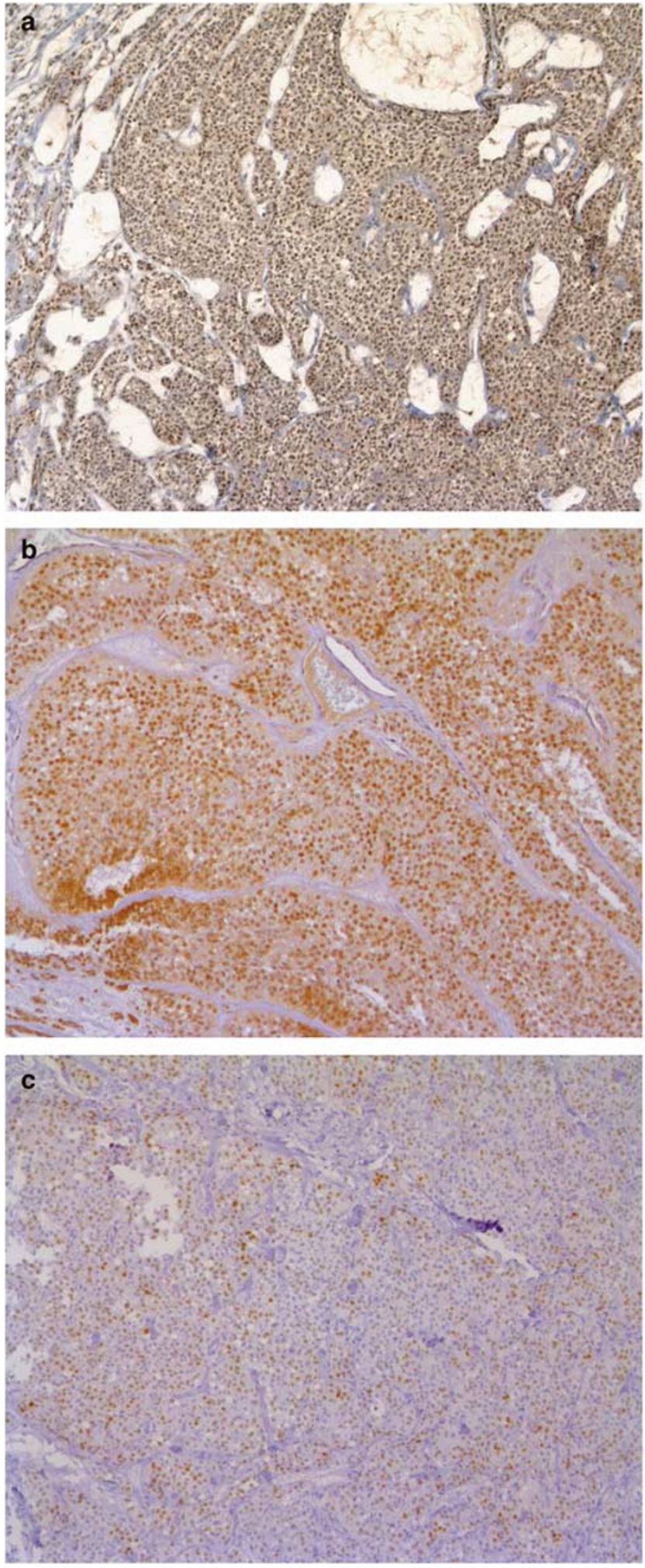

Figure 2 (a) Cyclin D1 expression in a solid pseudopapillary neoplasm. (b) p27 expression in a solid pseudopapillary neoplasm. (c) p21 expression in a solid pseudopapillary neoplasm.

striking features that make it distinct from all the pancreatic and extrapancreatic neoplasms. Apart from its biological features, that is occurrence in 
Table 2 Marker expression in the investigated tumor entities

\begin{tabular}{|c|c|c|c|c|}
\hline & $\beta$-catenin (aberrant) & Cyclin D1 & FLI-1 & CD56 \\
\hline Solid pseudopapillary neoplasm & $98 \%(91 / 93)$ & $69 \%(62 / 90)$ & $63 \%(58 / 92)$ & $97 \%(86 / 89)$ \\
\hline Pancreatic neuroendocrine tumor & $9 \%(2 / 22)$ & $14 \%(3 / 22)$ & $5 \%(1 / 21)$ & $50 \%(11 / 22)$ \\
\hline
\end{tabular}

Table 3 Cell cycle-associated markers in solid pseudopapillary neoplasms

\begin{tabular}{lc}
\hline Marker & Positive cases \\
\hline p16 & $2 / 14(14 \%)$ \\
p21 & $12 / 14(86 \%)$ \\
p27 & $14 / 14(100 \%)$ \\
pRb & $0 / 14(0 \%)$ \\
\hline
\end{tabular}

young women and low-grade malignancy, peculiar characteristics include its $\beta$-catenin mutation at exon $3^{1,2}$ and the accumulation of aberrantly expressed gene products of chromosome 11q.

It has been shown that $83-90 \%$ of solid pseudopapillary neoplasms have an activation of the Wntsignaling pathway due to mutation of the $\beta$-catenin gene in exon 3 . This mutation leads to a $\beta$-catenin that escapes intracytoplasmic phosporylation and, subsequent degradation and binds to the T-cell transcription factor (Tcf)/lymphoid enhancer-binding factor (Lef). The $\beta$-catenin-Tcf/Lef complex is then translocated to the nucleus, as indicated by nuclear expression of $\beta$-catenin, which has proved to be an immunohistochemical feature of solid pseudopapillary neoplasms. ${ }^{1}$ In the nucleus, the $\beta$ catenin-Tcf/Lef complex activates the transcription of several oncogenic genes, among them cyclin D1. ${ }^{15}$ This results in cyclin D1 overexpression in 70$100 \%$ of solid pseudopapillary neoplasms, as has been demonstrated in this and several other studies. ${ }^{1,2,16}$ One aim of our study was to clarify why the overexpression of the cell cycle-associated cyclin D1 in solid pseudopapillary neoplasms fails to increase their proliferative activity as it does in so many other neoplasms ${ }^{17-19}$ but instead results in a low growth rate.

It is known that the complex formed by cyclin D1 and its cyclin-dependent kinases (CDKs) phosphorylates the retinoblastoma $(\mathrm{Rb})$ protein. This causes the release of the transcriptional activator E2F, which blocks the transcription of genes required to drive the cell into the $S$ phase of the cell cycle. The ability of the cyclin D1/CDK4 complex to phosphorylate the $\mathrm{Rb}$ protein is inhibited by p21 and p $27 .{ }^{20} \mathrm{In}$ two solid pseudopapillary neoplasms, p21 and to a lesser extent p27 were shown to be upregulated. ${ }^{16}$ We investigated a subset of 14 tumors in our solid pseudopapillary neoplasms series and also found overexpression of p21 and p27 in all but two (for p21) solid pseudopapillary neoplasms. In the same subset of solid pseudopapillary neoplasms, which includes one metastasizing and one grossly invasive solid pseudopapillary neoplasm, we were, however, unable to detect hyperphosphorylated $\mathrm{Rb}$ using an antibody recognizing the (hyper) phosphorylated $\mathrm{Rb}$ protein. This inverse correlation of the expression patterns of p21 and p27 compared to pRb suggests an intact function of p21 and p27 as inhibitors of cell cycle progression at the G1 and G2 checkpoints. It is also known that estradiol and progesterone influence expression of p27 and p21 ${ }^{21,22}$ as well as cyclin D1 expression. ${ }^{23,24}$ Since solid pseudopapillary neoplasms consistently express the progesterone receptor, they may be hormone sensitive. Considering the influence and regulatory potential of estrogen and progesterone on the cell cycle and its components, this may lead to p27 and p21 expression and regulation of the cyclin D1/CDK4 complex. Whereas this balance works in solid pseudopapillary neoplasms, a decrease in p27 has been found in endocrine and nonendocrine tumors. ${ }^{25}$ Consequently, the inhibitory effect of p27 on the cyclin D1/CDK4 complex is diminished in these tumors. The lack of nuclear expression of p16 found in most solid pseudopapillary neoplasms in our series (except in two that occurred in the oldest patients) and usually indicates cell cycle promotion (since intact p16 leads to cell cycle arrest via the inhibition of the phosphorylation of the $\mathrm{Rb}$ protein by the cyclin D1/CDK complex) also seems to be overridden by the inhibitory effects of p21 and p27 on cell cycle progression. In concordance with the literature, accumulation of p16 is observed with advancing age and is not an effect caused by the tumor. ${ }^{26}$ Although these complex data have to be interpreted with caution, in the case of solid pseudopapillary neoplasms, they may indicate that the activated $\mathrm{Wnt} / \beta$-catenin-signaling pathway that is often associated with enhanced tumor cell proliferation appears to be antagonized by p21 and p27, which would help to explain the low growth rate of this special neoplasm.

It is unclear why p21 and p27 are overexpressed in solid pseudopapillary neoplasms. An altered p53 which commonly accounts for p21 and p27 overexpression can be ruled out, since p53 inactivation is an exceptional finding in solid pseudopapillary neoplasms., ${ }^{216}$ In solid pseudopapillary neoplasms, p21 and p27 are, therefore, to be upregulated by factors that so far are not known. In particular, there is no indication that the p21 and p27 overexpression is linked to the genetic alterations, which, in addition to the $\beta$-catenin mutation, are most conspicuous in the molecular profile of solid pseudo- 
papillary neoplasms. These changes concern the long arm of chromosome 11. The long arm of chromosome 11 is known as an area of imprinting, for example, for familial paragangliomas. ${ }^{27}$ The observed changes are not associated with gross chromosomal aberrations of this region, because such alterations were ruled out by comparative genomic hybridization of solid pseudopapillary neoplasms. ${ }^{28}$ However, despite the absence of gross chromosome abnormalities, this chromosomal area seems to be vulnerable to distinct genetic changes in solid pseudopapillary neoplasms, because it harbors a number of genes whose proteins are frequently found to be overexpressed. These proteins include cyclin D1, FLI-1, progesterone receptor and CD56. The overexpression of cyclin D1 may be explained by the activation of the Wnt/ $\beta$-catenin pathway, as discussed above. Since the gene locus for cyclin D1 maps closer to the centromere and not in continuity with the other three markers, there is no ready explanation for their overexpression. It is, however, of interest that the progesterone receptor and CD56 are also commonly expressed in pancreatic and other neuroendocrine tumors, suggesting that solid pseudopapillary neoplasms are related to neuroendocrine tumors, especially pancreatic neuroendocrine tumors. This assumption seems to be further supported by the synaptophysin positivity that solid pseudopapillary neoplasms exhibit in up to $22 \%$ of the cases. ${ }^{7}$ However, the evidence for a relationship between solid pseudopapillary neoplasms and neuroendocrine tumors also ends here, since solid pseudopapillary neoplasms have never been found to express other essential neuroendocrine features such as chromogranin A, peptide hormones ${ }^{7}$ or neurosecretory granules. ${ }^{29}$ We also were unable to confirm the reported frequent upregulation of cyclin D1 expression in pancreatic neuroendocrine tumors $^{30,31}$ on the basis of our data. In our series, we found that cyclin D1 expression is rare in pancreatic neuroendocrine tumors in contrast to solid pseudopapillary neoplasms. Moreover, FLI-1, which has been found to be increased in neuroendocrine neoplasms such as Merkel cell carcinomas, ${ }^{9}$ was expressed in only one pancreatic NET. This rare expression rate of FLI-1 in pancreatic neuroendocrine neoplasms contrasts with the frequent FLI-1 positivity in solid pseudopapillary neoplasms. Taken together, these findings suggest that solid pseudopapillary neoplasms are characterized by an accumulation of aberrantly expressed gene products on chromosome 11q that are also observed in NETs, but that these genes, apart from cyclin D1, neither show so far any clear molecular interaction with the activated $\mathrm{Wnt} / \beta$-catenin-signaling pathway, nor definitely support a neuroendocrine origin of solid pseudopapillary neoplasms. The marker accumulation on chromosome 11q, therefore, remains an interesting genetic finding of yet unknown significance for the molecular pathogenesis of solid pseudopapillary neoplasms.
In summary, our results may suggest that the cyclin-dependent kinase inhibitors p21 and p27 play a role in stopping the activated $\mathrm{Wnt} / \beta$-cateninsignaling pathway, resulting in a low tumor growth rate. The factors that govern the overexpression of p21 and p27; however, have yet to be explained. The remarkable clustering of proteins whose genes map to chromosome 11q22-24 in solid pseudopapillary neoplasms may indicate that this is a region of potential significance for the tumorigenesis of solid pseudopapillary neoplasms and needs further investigation.

\section{Acknowledgements}

We thank Ms Maike Pacena and Mrs Anja Bredtmann for their excellent technical assistance. We are especially grateful to Alexander Claviez, MD, for help with the statistical analysis.

\section{Disclosure/conflicts of interest}

The authors declare that they have no conflict of interest.

\section{References}

1 Tanaka Y, Kato K, Notohara K, et al. Frequent b-catenin mutation and cytoplasmic/nuclear accumulation in pancreatic solid-pseudopapillary neoplasm. Cancer Res 2001;61:8401-8404.

2 Abraham SC, Klimstra DS, Wilentz RE, et al. Solidpseudopapillary tumors of the pancreas are genetically distinct from pancreatic ductal adenocarcinomas and almost always harbor b-catenin mutations. Am J Pathol 2002;160:1361-1369.

3 Sporny S, Slowinska-Klencka D, Ratynska M. Cyclin D1 expression in primary thyroid carcinomas. Neuro Endocrinol Lett 2005;26:815-818.

4 Igarashi T, Jiang SX, Kameya T, et al. Divergent cyclin $\mathrm{B} 1$ expression and Rb/p16/cyclin D1 pathway aberrations among pulmonary neuroendocrine tumors. Mod Pathol 2004;17:1259-1267.

5 Van Diest PJ, Michalides RJ, Jannink L, et al. Cyclin D1 expression in invasive breast cancer. Correlations and prognostic value. Am J Pathol 1997;150:705-711.

6 Fernandez V, Hartmann E, Ott G, et al. Pathogenesis of mantle-cell lymphoma: all oncogenic roads lead to dysregulation of cell cycle and DNA damage response pathways. J Clin Oncol 2005;23:6364-6369.

7 Kosmahl M, Seada LS, Jänig U, et al. Solid-pseudopapillary tumor of the pancreas: its origin revisited. Virchows Arch 2000;436:473-480.

8 Notohara K, Hamazaki S, Tsukayama C, et al. Solidpseudopapillary tumor of the pancreas. Immunohistochemical localization of neuroendocrine markers and CD10. Am J Surg Pathol 2000;24:1361-1371.

9 Llombart B, Monteagudo C, Lopez-Guerrero JA, et al. Clinicopathological and immunohistochemical analysis of 20 cases of Merkel cell carcinoma in search of prognostic markers. Histopathology 2005;46:622-634. 
10 Cao D, Antonescu C, Wong G, et al. Positive immunohistochemical staining of KIT in solid-pseudopapillary neoplasms of the pancreas is not associated with KIT/PDGFRA mutations. Mod Pathol 2006;19: 1157-1163.

11 Sihto H, Sarlomo-Rikala M, Tynninen O, et al. KIT and platelet-derived growth factor receptor alpha tyrosine kinase gene mutations and KIT amplifications in human solid tumors. J Clin Oncol 2005;23: 49-57.

12 Tamborini E, Bonadiman L, Negri T, et al. Detection of overexpressed and phosphorylated wild-type kit receptor in surgical specimens of small cell lung cancer. Clin Cancer Res 2004;10:8214-8219.

13 Perren A, Komminoth P, Heitz PU. Molecular genetics of gastroenteropancreatic endocrine tumors. Ann N Y Acad Sci 2004;1014:199-208.

14 DeLellis RA, Lloyd RV, Heitz PU, et al. Pathology and Genetics of Tumours of Endocrine Organs. WHO Classification of Tumours. IARC Press: Lyon, 2004.

15 Tetsu O, McCormick F. Beta-catenin regulates expression of cyclin D1 in colon carcinoma cells. Nature 1999;398:422-426.

16 Müller-Höcker J, Zietz CH, Sendelhofert A. Deregulated expression of cell cycle-associated proteins in solid pseudopapillary tumor of the pancreas. Mod Pathol 2001;14:47-53.

17 Barnes DM. Cyclin D1 in mammary carcinoma. J Pathol 1997;181:267-269.

18 Michalides R, van Veelen N, Hart A, et al. Overexpression of cyclin D1 correlates with recurrence in a group of forty-seven operable squamous cell carcinomas of the head and neck. Cancer Res 1995;55: 975-978.

19 Sheyn I, Noffsinger AE, Heffelfinger S, et al. Amplification and expression of the cyclin D1 gene in anal and esophageal squamous cell carcinomas. Hum Pathol 1997;28:270-276.

20 Sherr CJ, McCormick F. The RB and p53 pathways in cancer. Cancer Cell 2002;2:103-112.
21 Sutherland RL, Prall OW, Watts CK, et al. Estrogen and progestin regulation of cell cycle progression. J Mammary Gland Biol Neoplasia 1998;3:63-72.

22 Groshong SD, Owen GI, Grimison B, et al. Biphasic regulation of breast cancer cell growth by progesterone: role of the cyclin-dependent kinase inhibitors, p21 and p27(Kip1). Mol Endocrinol 1997;11:1593-1607.

23 Said TK, Conneely OM, Medina D, et al. Progesterone, in addition to estrogen, induces cyclin D1 expression in the murine mammary epithelial cell, in vivo. Endocrinology 1997;138:3933-3939.

24 Faivre E, Skildum A, Pierson-Mullany L, et al. Integration of progesterone receptor mediated rapid signaling and nuclear actions in breast cancer cell models: role of mitogen-activated protein kinases and cell cycle regulators. Steroids 2005;70:418-426.

25 Lloyd RV, Jin L, Qian X, et al. Aberrant p27kip1 expression in endocrine and other tumors. Am J Pathol 1997;150:401-407.

26 Krishnamurthy J, Ramsey MR, Ligon KL, et al. p16INK4a induces an age-dependent decline in islet regenerative potential. Nature 2006;443:453-457.

27 Bikhazi PH, Roeder E, Attaie A, et al. Familial paragangliomas: the emerging impact of molecular genetics on evaluation and management. Am J Otol 1999;20:639-643.

28 Tiemann K, Kosmahl M, Ohlendorf J, et al. Solid pseudopapillary neoplasms of the pancreas are associated with FLI-1 expression, but not with EWS/FLI-1 translocation. Mod Pathol 2006;19:1409-1413.

29 Klöppel G, Morohoshi T, John HD, et al. Solid and cystic acinar cell tumour of the pancreas. A tumour in young women with favourable prognosis. Virchows Arch A Pathol Anat Histol 1981;392:171-183.

30 Guo SS, Wu X, Shimoide AT, et al. Frequent overexpression of cyclin D1 in sporadic pancreatic endocrine tumours. J Endocrinol 2003;179:73-79.

31 Chung DC, Brown SB, Graeme-Cook F, et al. Overexpression of cyclin D1 occurs frequently in human pancreatic endocrine tumors. J Clin Endocrinol Metab 2000;85:4373-4378. 